\title{
The McDonaldization of Everything: Teaching Weber to Undergraduates
}

\author{
Howard E. Aldrich (University of North Carolina at Chapel Hill) \\ Stephen Lippmann
}

KEYWORDS: Management of Companies \& Enterprises, Management, Organization, Teaching Methods.

Max Weber argued that the process of rationalization transformed social life forever. By loosening the hold of tradition, rationalization led to new practices that were chosen due to their efficiency. He proposed that the superiority of the bureaucratic form would cause it to dominate all forms of human organization. And indeed, social order in the Western world changed drastically with the rise of two great forces of modernity: capitalism and bureaucracy. Notably, however, Weber did not include "entrepreneurship" as one of those great forces.

Weber's ideas continue to inform sociological theorizing today and are vital for students taking courses in organizations, management, strategy and entrepreneurship. However, like many classic texts of sociology, his arcane language and obscure examples can easily lead to confusion and panic for undergraduates. Students' confusion is compounded because many of the processes and structures that comprise the substance of Weber's writings are virtually omnipresent in American culture. These structures have influenced students' lives from the day they were born, which makes it much more difficult for students to grasp their socially constructed nature. Students simply take bureaucracy for granted.

This article describes a hands-on approach to teaching Weber's ideas that is accessible to undergraduates and helps students observe rationalization and rationality in action. We use Ritzer's McDonaldization of Society as a pivotal link between students' observations and Weber's theory of bureaucracy and rationality. Ritzer proposes that "McDonaldized" organizations are characterized by efficiency, calculability, predictability and control through technology - which bear an obvious resemblance to Weber's original definition of "bureaucracy."

During the unit, students read Max Weber's (1946) essay "Bureaucracy" and selections from Ritzer's McDonaldization of Society. Upon completion of the exercises and the unit, students should show not only an improved understanding of Weber's and Ritzer's theoretical constructs, but also better comprehend how rationalizing processes affect what entrepreneurs do and how they do it.

The McDonaldization of Society is well-suited to undergraduate courses. Its style and content are easily digested, and the cases selected to demonstrate the McDonaldization concept are familiar to most students. Because fast-food outlets are easily accessed from campus, they provide excellent opportunities for student observation. A reviewer for this assignment suggested it also would be good for Ph.D. students, as it gives them an opportunity to reflect on how the theory that they normally read about as arid and abstract could be brought to life through field observations.

\section{Using the Exercise in Entrepreneurship Classes}

This active learning exercise is especially valuable for courses on entrepreneurship. First, in a course section on startups, this exercise can be used to help students understand the difference between the highly formalized structures they are accustomed to in their everyday lives versus the daunting problems faced by entrepreneurs who are trying to create routines and formalized structures for their fledgling organizations. This exercise might be paired with a reading or two that describes the uncertainty and even chaos that nascent entrepreneurs face when they are trying to organize their new ventures (Sarasvathy, 2009). We don't recommend a field visit to a nascent entrepreneur, as such people have enough to do without students poking about their work! 
Second, in a section on organizational growth, especially early-stage growth, this exercise can be used to help students understand the difficulties that entrepreneurs face in creating structures that facilitate and control increased specialization. The exercise gives instructors an opportunity to ask students to reflect on the principles of job design and evolution in response to organizational growth. To what extent can the bureaucratic procedures they've observed be implemented in new and fast-growing ventures? They can also ask students to discuss the differences between intentional job design and more emergent and unintentional workplace outcomes.

Third, in a section on innovation and creativity, this exercise can be used to ask students to reflect on the likelihood of innovation occurring in the highly formalized structures they observed, versus what might occur in a startup. Again, this discussion will work best if paired with an article on innovation and creativity, such as Aldrich and Martinez (2015).

The exercise is carried out over three consecutive classes. It can be done in fewer class meetings, but for the full effect, we suggest setting aside three classes for it.

\section{Class 1}

The first day of the unit is intended to introduce students to the material and to get them comfortable with treating McDonald's as an analytical case worthy of social science investigation. We also begin to discuss the major dimensions of Ritzer's thesis.

Readings: For the first day of class, students should read the following:

- Weber's (1946) essay "Bureaucracy"

- Ritzer's McDonaldization chapters 1 and 2

Pre-Test: Either on-line or on paper, at the start of class, students are given the following ungraded quiz for use as a baseline from which to judge the success of the exercise (all quizzes and required forms are given in the Appendix):

\section{Pre-Unit Quiz on Max Weber:}

1. Define bureaucracy.

2. Why has bureaucracy spread in the modern world?
3. Do you think that bureaucracy and rationality are equivalent? Why or why not?

4. How relevant are Weber's ideas for understanding the twenty-first century? Why?

\section{After completing the pre-unit quiz, move to the next activity:}

Individual Reflection: Students are asked to individually set down on paper, in as much detail as possible, the steps involved when someone eats at McDonald's or another fast food restaurant, using the following form:

\section{In-Class Discussion Form \#1: Thinking about McDonald's}

1. Please recreate, on paper, the steps taken when ordering a meal at McDonald's. In as much detail as possible, outline the steps a customer takes when ordering and eating a meal at McDonald's, from the moment s/he enters the restaurant to the moment s/he leaves. Please include any gestures or language that is typical in this encounter.

2. Have you ever worked in a fast food restaurant? Which one? What did you do there?

Group Reflection: After this individual recollection exercise is completed, students meet in groups of four. We typically create the groups during the first week of class, based on students' responses to questions on their majors, hometowns and outside interests. We strive for groups that are diverse in gender and ethnicity. These groups remain together throughout the term, but some instructors like to change group memberships occasionally. We find that maintaining the same group members builds solidarity and lets them develop a rhythm of working together.

In their groups, students complete two tasks. First, they share the results of their recollections for approximately 7 to 10 minutes. Second, they discuss new questions, again taking 7 to 10 minutes. Note that all groups do NOT have to finish - waiting until all have finished makes an instructor hostage to the slowest group! Instead, walk around the room and stop the discussion when MOST have finished:

1. Did you ever have any bad experiences at McDonald's? 
2. Were any of your expectations unfulfilled?

3. Compare McDonald's to a non-fast food restaurant. In what ways do they differ? How are they the same?

Class Discussion: The class gathers again as a whole to discuss each group's answers. We put their answers on the board. If the students have not already done so, we make certain that each of the points on the board is been linked to a concept from Ritzer. In the discussion, students typically not only note the predictability of the process, but also emphasize the role that customers' expectations play in the process of rationalization. After completing the discussion, we sum up by going over the goals of the observational exercise described below.

Introduce Observation Activity: This form is to be completed prior to the next class. Be sure to leave enough time at the end of class to thoroughly discuss it. Emphasize its importance and ensure everyone is prepared to conduct observations. We suggest they visit the fast food restaurants in small groups, to give them confidence and support.

\section{Observation Form \#1: Observing McDonald's}

Goals of the assignment: to observe the interaction at a fast food restaurant (preferably McDonald's, but it could be another one, such as Burger King, Chick-Fil-A or Hardee's, but NOT a pizza restaurant) and describe what you see.

Pick a site: Choose a fast food restaurant that has counter service. Sit at a booth where you can observe what is going on at the counter and behind the counter. Observations to be filled out as you observe or shortly thereafter:

1. What is the complete cycle of interaction between a customer and the employees behind the counter? Write it out in terms of its steps.

2. What does the employee say?

3. What does the employee do?

4. How many different jobs are there behind the counter? Write down some possible job titles for them.

5. Is someone obviously in charge? How do you know?

6. How is he/she controlling what the employees are doing?

Homework: Before the next class, students are asked to:

- Complete the observation activity discussed at the start of class. The form is turned in on-line and students are given a check mark for completing it.

- Read chapters 3-5 of Ritzer's McDonaldization.

\section{Class 2}

Class 2 is intended to reinforce the concept of predictability and to illustrate and explain efficiency and calculability, as Ritzer uses the terms. Ask students to print out and bring to class their McDonald's observation form.

Group Reflection: Students share the results of their fast food observations with their team members. Teams are also asked to compare their observations to the steps they drew up during the previous class meeting. They discuss the structure of the establishment they observed and how the managers controlled the behavior of employees. This part can typically be carried out in 7 to 10 minutes. As before, not all groups need to "finish" their discussion before you bring them back together as a class.

Group Activity [optional, if time]: Teams prepare a skit in which they portray a typical interaction between customers and employees, and two or three skits are presented in front of the class.

Class Discussion: As a class, we discuss:

1. Why students' recollections of the process at McDonald's closely resembled what they actually observed, and in the process, we demonstrate the predictability dimension of Ritzer's thesis.

2. The structure of the organization and how their empirical observations demonstrate (or occasionally fail to demonstrate) the efficiency dimension of Ritzer's thesis. During the discussion, the class is also asked to compare the following ideas to those discussed in the previous Weber readings. 
3. We discuss Weber's six dimensions of bureaucracy and whether the fast-food restaurants they observed conform to the definition.

4. We ask the students to discuss how the six dimensions of bureaucracy outlined by Weber might lead to predictable and efficient outcomes.

5. To what extent can entrepreneurs design their own organizations to avoid some of the irrationalities Ritzer points out?

Homework: Before the next class, students are asked to:

- Read chapters 7-9 of Ritzer's McDonaldization

\section{Class 3}

We spend the last day of the exercise summarizing and evaluating Weber's and Ritzer's theories. The class discussion is centered on two major themes: The first is what Ritzer calls "the irrationality of rationality," and the second involves an analysis of the merits and shortcomings of Ritzer's theoretical framework.

Class Discussion: We try to link students' insights to the "irrationalities" Ritzer highlights, including problems such as the dehumanization of work in McDonaldized settings, red tape, poor-quality work and products, and the misguided anger of employees and customers. We begin the discussion with the following prompts:

1. Does the process at McDonald's compromise quality? Why or why not?

2. Given the way McDonald's is structured, is there any way to recover some of the quality that is lost?

3. Do entrepreneurial firms face the same problems or are they better off because they start without a pre-set structure?

In an upper-level course, students are not only expected to understand the theories they read but also to be able to engage in the process of theory construction and criticism. This goal leads to the next class discussion.

Class Discussion: Students are encouraged to think about the ways in which Ritzer has updated and built upon Weber's original theory of rationalization, while at the same time acknowledging the contemporary relevance of Weber's theory. Because Ritzer's book is so accessible and deals with such a familiar topic, it provides ample opportunities for students to sharpen these skills. The following questions guide this conversation:

1. How useful are the four dimensions Ritzer uses as an analytic tool?

2. Are they exhaustive?

3. What assumptions does Ritzer make?

4. How does this framework apply to the other examples Ritzer uses?

5. What are Ritzer's units of analysis?

6. Can we derive testable hypotheses from this theory?

7. Is the framework value free?

We spend the remainder of the last day applying the theories to more sophisticated spheres of social life. Fast food provides students with an accessible and familiar case on which to build their understanding of the theories. However, we have found that more complex institutions, such as medicine and higher education, make fine examples for challenging and enhancing students' understanding of rationalization and bureaucracy. We asked the students to consider the role of entrepreneurs in creating innovative forms that don't simply reproduce existing templates, and whether entrepreneurs can thereby escape the "Iron Cage of Rationality" posited by Weber.

Conclusion: As the process of rationalization becomes more fully realized, it is crucial that students comprehend the impact of these forces on the social world. By utilizing active learning techniques and Ritzer's popular and accessible The McDonaldization of Society, we have developed a unit on rationalization that has proven very successful in piquing students' interest in the process and improving their understanding of it. We feel that these exercises clarify both rationality and McDonaldization by allowing students to venture out into the McDonaldized world and see the process in action for themselves. Contrasting the highly formalized, efficient and predictable structures of bureaucracies with the task facing entrepreneurs creating startups leads to lively discussions.

\section{References}

Aldrich, Howard E. and Martha A. Martinez. 2015. "Why Aren't Entrepreneurs More Creative? Conditions Affecting Creativity and Innovation in Entrepreneurial Activity. Pp. 445-456 in Christina E. Shalley, Michael A. Hitt, and Jing Zhou, editors, The Oxford Handbook of 
Creativity, Innovation, and Entrepreneurship: Multilevel Linkages. Oxford: Oxford University Press.

Lippmann, Stephen and Howard E. Aldrich. 2003. "The Rationalization of Everything? Using Ritzer's McDonaldization Thesis to Teach Weber." Teaching Sociology, 31, 2 (April): 134-145

Ritzer, George. 2015. The McDonalization of Society, eighth edition. Thousand Oaks, California: Sage Publications.

Sarasvathy, Saras. 2009. Effectuation: Elements of Entrepreneurial Expertise. Cheltenham, UK: Edward Elgar Publishing.

Weber, Max. 1946. "Bureaucracy." Pages 196-244 in From Max Weber: Essays in Sociology.

Hans Gerth and C. Wright Mills, eds. New York: Oxford University Press. 


\section{Handouts and Forms Used in the Weber/McDonaldization Exercise Appendix1: Pre-and Post-Unit Quiz on Max Weber}

1. Define bureaucracy.

2. Why has bureaucracy spread in the modern world?

3. Do you think that bureaucracy and rationality are equivalent? Why or why not?

4. How relevant are Weber's ideas for understanding the 21st century? Why?

\section{Appendix 2: Observation Form \#1 -- Observing McDonald's}

Goals of the assignment: to observe the interaction at a fast food restaurant (preferably McDonald's, but it could be another one, such as Burger King, Chick-fil-A, or Hardee's, but it cannot be a pizza restaurant) and describe what you see.

Pick a site: choose a fast food restaurant that has counter service. Sit at a booth where you can observe what is going on at the counter and behind the counter.

Observations to be filled out as you observe or shortly thereafter:

1. What is the complete cycle of interaction between a customer and the employees behind the counter? Write it out in terms of its steps.

1. What does the employee say?

2. What does the employee do?

2. How many different jobs are there behind the counter? Write down some possible job titles for them.

3. Is someone obviously in charge? How do you know?

4. How is he/she controlling what the employees are doing?

\section{Appendix 3: In Class Discussion Form \#1 - - Thinking about McDonald's}

1. Please recreate, on paper, the steps taken when ordering a meal at McDonald's. In as much detail as possible, outline the steps customers take when ordering and eating a meal at McDonald's, from the moment they enter the restaurant to the moment they leave. Please include any gestures or language that is typical in this encounter.

2. Have you ever worked in a fast food restaurant? Which one? What did you do there?

\section{Appendix 4: Observation Form \#2 -- Use of Nonhuman Technologies to Control Humans}

Choose a location on campus (or off, if you wish) where you can observe humans being controlled by some form of nonhuman technology. In class, we mentioned traffic lights, entrances to buildings and ATMs.

Answer the following questions:

1. Where did you conduct your observations?

2. Who was being controlled (describe by their statuses and roles)?

3. How many people were being controlled?

4. Describe the technology used to control them and explain briefly how it worked.

Appendix 5: in Class Discussion Form \#2 - - Nonhuman Technology for Control 
In your team, please share the results of your observations (Observation Form \#2: The Use of a Nonhuman Technology to Control Humans) and answer the following questions:

1. Explain to each other (1) where you conducted your observations; (2) who was being controlled; (3) how many people were being controlled; and (4) how the process actually worked.

2. Did the process always work (people were always control) or did it NOT work sometimes?

1. If it did not always work, why not?

2. if it did always work, why?

3. Choose ONE of the examples from your group and be prepared to explain it to the class. If you can, create a skit for role-playing simulation to show how it worked

Additional Search Terms: entrepreneurship courses, teaching ideas, teaching resources, classroom ideas, entrepreneurship classes, business schools, business school classes, entrepreneurship students, professors 